\section{B A Institute of \\ YK Business Administration \\ 光 \\ Karachi \\ Leadership and Ideas for Tomorrow}

\section{Business Review}

Volume 1 Issue 1

July - December 2006

7-1-2006

\title{
Knowledge entrepreneurship: A new paradigm for organizational performance
}

\section{S.M Taha}

Institute of Business Administration, Karachi, Pakistan

Follow this and additional works at: https://ir.iba.edu.pk/businessreview

Part of the Organizational Behavior and Theory Commons

\section{(c) (7)}

This work is licensed under a Creative Commons Attribution 4.0 International License.

\section{Recommended Citation}

Taha, S. (2006). Knowledge entrepreneurship: A new paradigm for organizational performance. Business Review, 1(1), 96-105. Retrieved from https://doi.org/10.54784/1990-6587.1097

This article is brought to you by iRepository for open access under the Creative Commons Attribution 4.0 License and is available at https://ir.iba.edu.pk/businessreview/vol1/iss1/9. For more information, please contact irepository@iba.edu.pk. 


\title{
ARTICLE
}

\section{Knowledge Entrepreneurship: A New Paradigm for Organizational Performance}

\author{
S.M. Taha
}

T ast decade of the twentieth century experienced cataclysmic changes in organizations' $ـ$ structure and their performance. Organizations are now considered as sentient being. They think through their systems; they plan through their functionaries; they perform through their resources (human and capital assets). Now they have become a basic building bloc of our today's corporate world. We can list several themes that brought changes in culture, design and environment of contemporary organizations all over the world. These include: globalization, interdependence and free markets economy. These trends forced countries and organizations to reshape their economic and business strategies. One factor, however that can rightly be counted as 'the factor' that alone altered the very nature of organizations, that is the 'Knowledge Boom'.

Knowledge Boom gave birth to the new economy in which brainpower has become more critical resource than the machine power. Microelectronic revolution breaks all possible barriers to knowledge and information. This flood of knowledge has brought significant change in organizations in developed countries and gave new impetus for global competition and new challenges to the weaker countries of the south. Pakistan is one of them. Pakistan's economy indicates positive trend in past five years but still not to be called as strong economy.

Pakistan's contribution in creating knowledge is minuscule in the global knowledge pool as compared to other developing countries with the same colonial history. In addition to that Pakistan's social and cultural milieu and value-based mindset is less responsive to knowledge and innovation.

This research focus on three queries:

1. How would we define knowledge in global and regional setting?

2. What are the changing demands that a 'knowledge based economy' poses on organizational function?

3. What are the implications of knowledge based economy on the present state of human resources in Pakistan?

To answer these queries we look at economies where knowledge entrepreneurs have changed the nature of organizations. Lets take a retrospective view of organizational change through knowledge management in United States. American business invested $\$ 1$ trillion to bring change in office automation during 1980s. Knowledge entrepreneurs set out new processes of redesigning organizations. This also led to a new thinking 
that small size organization can perform more efficiently than large size. Managers concentrated their thinking that how small self-managed units may perform welldefined services? How intelligent information systems can integrate all operations into a working whole with the help of Local Area Networks (LANs)?

Working on these queries, management thinkers finally realized that small business units could be effective by developing a self-directed team of knowledge workers that is given almost total command over product design to manufacturing, sales, services, and disposal. This job enrichment process had profound impact on the nature of employment. Organizations gradually offered performance-based salary rather than position-based. Contractual employment increased that also increased healthy competitions not only among organizations but also among the knowledge-based workers.

Under these contractual appointments, workers' rights were linked with responsibilities. The interdependent link between rights and responsibilities ensures the success of participative management. If workers exercise freedom in performing the task without being accountable for desired outcome, the organization cannot survive. Contractual employment assured performance and provided enhanced opportunity for earning along with the desirable working conditions.

As information systems become user-friendly and inexpensive, they facilitated convenient ways to substitute traditional office management. Rather than permanent employees working 9 to 5 in the same building, electronically mediated working benign the previous restrictions of time and place and become a viable alternative to the real things, as information technology becomes increasingly convenient.

For instance, Compaq Computer automated its routine sales work in 1993 by offering clients toll-free information lines for inquiries, and then shifted its entire sales people into home offices to make them more effective. Each salesperson was provided stateof-the-art information systems, such as fax, copier, high-powered PC notebook, and cellular phone, as well as other needed support. Revenues doubled while the sales force dropped by one-third. IBM made the similar changes. This trend marked a major shift to an independent, more mature mode of self-employment. Contingent workers have become true knowledge entrepreneurs who take charge of their careers by running their own businesses or moving from company to company as contractors. They have their knowledge toolkit and companies call them, if they require their services.

These developments had taken place all over the world in the decade of 1990s. Pakistan's business environment is also vulnerable to these developments. Before defining the term 'knowledge economy' in local context, a brief analysis of Pakistani society seems pertinent to understand the nature and future of knowledge economy in Pakistan.

Pakistan has primarily an agricultural base economy. Its society divides on several lines that includes: provincial, sectarian, linguistic and classes. Sub national identities are realities of Pakistani society. In addition to that Pakistan's social milieu is composed 
of feudal, tribal and local loyalties that are greater than the national loyalties. These divisions segregate the entire society and hamper the holistic growth of the national economy. It is why the national landscape sharply depicts a wide gap between developed and underdeveloped areas in Pakistan.

Side effects of these fault lines are devastating. Education system is one of the examples. These divisions in the society very unfortunately developed an education system that further segregates Pakistani society. This eventually produced class-based human resources years after years that are now evident in organizational culture in Pakistan. Organizations in Pakistan are dominantly hierarchical, boss-culture is common, dominance is desirable and subordination is required. In Pakistani society, class interest or identity interest (provincial, linguistic, and sectarian) had replaced the merit culture at the very inception of the country. Stereotypes, biases, nepotism and favoritism overwhelmed the organizational culture in Pakistan. Quality education is an expensive commodity in Pakistan that is available to few privileged classes that dominate destinies of unprivileged classes. This class gradually assumes the status of elite class in Pakistani society. Even with good education many people are marginalized in Pakistani society, leading to unemployment, crime and other disorders. What Charles Murray warns in his book The Bell Curve can be seen in Pakistan that 'cognitive elites' are ruling the country with a developed caste system. These elites formulizes into an effective power of status quo and resist change in the very structure of the state, society and economy of this country. But now they learn through the rampant and rapid globalization that the change is inevitable if not in the mindset but essentially in the way they run the businesses.

For the last five years Pakistan's policies are consistent that attracts foreign investors. Pakistan boldly accepted the challenge of international competition when it joined World Trade Organization in 2000. Pakistan's industrial growth rate and manufacturing sectors indicate positive signs during the last five years. There is no doubt that Pakistan's economy is growing but still it has to do a lot to compete with the developed world. And the best way to compete with, is to bring change in the mindset, in organizational designs, cultures and operations. These changes can only come through the knowledge acceptance, knowledge adoption and knowledge creation that cater the need of the local enterprises and effectively respond to global competition.

The business class in Pakistan now has realized that the organizations will need an exceptional degree of flexibility. Self-managed work teams are essential to increase production as well as improve management that may effectively meet a rush of demand for production and services or may radically restructure the organizations.

This research conducted surveys and interviewed number of people (employees and employers). I purposely selected three sectors where the change in organizational working and culture was evident. These are: banking sector, emerging services sector, and marketing strategies. In the banking sector, car financing units and credit cards units present altogether a new culture at workplace. Flexibility, job enrichment and product knowledge increase employees' motivation. In addition to that pay-for- 
performance principle is associated with commission on each sale. This boost up the sales and eventually contributed in the overall performance of organizations. Top management expressed the view that now organizations are clustering into entrepreneurial units that with the passing of time will work together and form internal market within a corporate community. Top management from the banking and services sector is of the view that this internal market will integrate the interest of investors, workers, clients, business partners and the public.

This change in thinking is not because of altruism but because of the relentless advance in global competition and boom in information technology. Information boom pushes economies into a new phase that is rightly called as knowledge economy. Now the belief is getting strength in Pakistan that knowledge-based economy makes cooperation a competitive advantage.

Knowledge economy sets off and entails vibrant modification not only at the broader level of technology, science, and education policies, but also at the micro level represent by firms. Firms now are increasingly becoming players in a 'hyper-competitive' game and engaging in extensive knowledge sourcing from all sorts of knowledge producers - whether they be suppliers, customers and clients, universities or employees controlling critical knowledge to support the knowledge-based strategies that are appropriate for the 'new competition'.

Knowledge itself produces nothing unless it is processed into an operation. It is not only required in big business rather it works efficiently in small and medium enterprises. How knowledge-based innovation can be used in modernizing Pakistan's industrial and business structure is the critical question that we should not ignore now. Modernization cannot come without knowledge that developed societies have already built. An urge for modern management will convert knowledge from social ornament and luxury into the true capital of any economy.

We have little systematic empirical evidence that speaks directly to the issue of how the knowledge economy impacts on organization and strategy. Moreover, the existing theories in economics and business administration with respect to grappling with these issues are unclear. There is a diversity of perspectives. But this diversity is not contradictory to each other. They are rather complementary in theorizing the role of knowledge in modernization of management. The ongoing restructuring of management and organization practices designed to cope with an increasingly complex and rapidly changing knowledge-based economy has received increasing attention from scholars of diverse disciplines and fields.

Since 1985, the mode of the representation of knowledge has become more performative. In Pakistan, the key knowledge-making role has moved out of the universities into the professional firms. These professional firms and businesses would be the key player in transforming the organizational culture and performance. Performative knowledge is distinguished by the ideal that knowledge should be actionable and commercially useful. Pakistan's leadership has to realize that creating and seeking knowledge is an 
unending process. It leads to new innovation and make the previous one less useful if not obsolete. So economies that are stagnant with the traditional style of production and management will be wiped out soon and will have devastating impact on the state and its citizens.

Management philosophers, university professors, industrial engineers and government personnel in Pakistan should sit together and frame a strategy that will give boost to the national economy. The vital questions before them are how to acquire or create knowledge? How to apply knowledge? And how to manage knowledge? There are three fundamental modes of thinking to pursue the knowledge:

1. A shift from an industrially based economy to knowledge or informationbased economy demands a sophisticated knowledge management system that has capacity to secure a competitive edge and learning innovation.

2. The new source of wealth is knowledge, and not labor, land, or financial capital. It is the intangible, intellectual assets that must be managed.

3. The crucial challenge of the knowledge-based economy is to foster actionable innovation.

These critical ways of thinking will certainly lead to a change in operations and management practices in our organizations. Though we do not have empirical studies to substantiate this assertion, theoretically it seems very much logical that the following outcome will happen:

- Organization will go under redesigning and will adopt techniques and processes that create, protect and use known knowledge.

- Organization will create environments and activities to discover and release knowledge that is not known.

- Organization will articulate purpose and nature of managing knowledge as a resource and embodying it in other initiatives and programs.

- Instead of constantly reengineering and downsizing, organization will keep the talented people.

- The reuse of knowledge saves work, reduces communications costs and allows a company to take on more projects.

\section{Organizational Change Through Knowledge Management}

Generating organizational knowledge invariably means converting the tacit knowledge of the individual into explicit knowledge accessible by all. Information technology is most effective when it enables this social process. Through the knowledge management system, organizations must think through their technological systems. Technology 
such as Internets and advanced collaborative software are the best and proven techniques of Knowledge Management. Information Technology will blur the lines between departments and operating divisions, and will make a positive breach in the hierarchical system. Knowledge management system facilitates individual, team and group learning process that must become the true driver of organizational performance.

There are three fundamental processes that sustain profound changes such as the introduction of a knowledge management system: 1) developing networks of committed people; 2) improving business results; 3 ) enhancing personal results.

For achieving sustainability, there must be a focus on learning and learning how to harness the learning capabilities that lead to innovation. Hierarchical control must be put aside for sustainable change. Organizations have to develop informal networks so that people can share their knowledge and help one another. Horizontal management is much better to understand the value of intangible assets over tangible assets which is the essence of knowledge management. Vertical control becomes less important in organizations, while horizontal co-ordination becomes more important, and people increasingly co-operate across formal organizational boundaries. Industrial and business leadership need to examine the human and intellectual capital in Pakistan, which is the potential source of their performance.

\section{Understanding the Paradigm of Knowledge Management}

The nature and structure of knowledge have gone through tremendous changes in last two decades. How to create, apply and manage knowledge is required to understand its nature and very structure. In my view, knowledge travels through a highly complex global web system that involves basic research, engineering and continuous innovation through a continuous feedback system. Figure 1.1 explains the domain of knowledge.

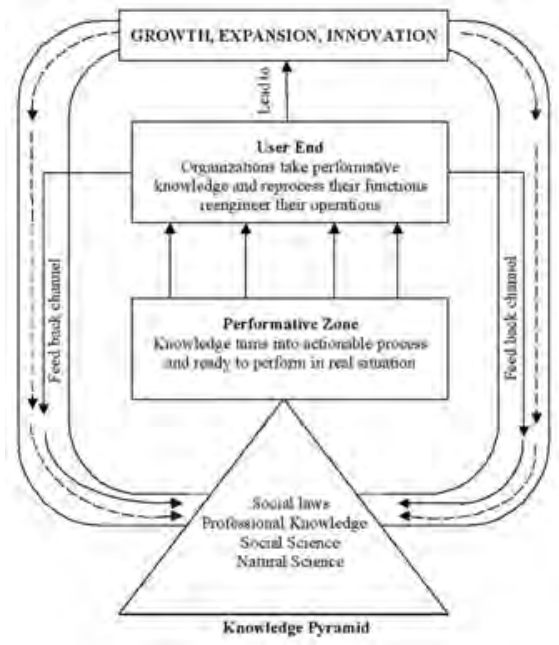

Figure 1.1: Knowledge-based Organizational Growth 
The core of the process is the diffusion of knowledge. 'Diffusion is the process by which an innovation is communicated through certain channels over time among the members of a social system'. This process brings together the knowledge products from almost all field of studies. Simulation of knowledge produces performative products of knowledge and supply to the desired users. The pyramid in the above picture takes a continuous feedback that ensures continuous process of innovation and performation and sends it back to the desired users. The leading principle of every organization is its goals. The goals can be commercial, social or idealistic. Organizations decide how and which product of knowledge is useful for its goals. There are three fundamental questions organizations must think upon before taking decision of using knowledge products: how to use knowledge products efficiently and effectively? Do organizations have infrastructure to apply that knowledge? Do organizations have human resource to handle the operations of knowledge?

Information Technology may answer these questions. The convergence of telecommunication and computer technology has given rise to Information technology. IT has radically altered a number of aspects of both the way we live and the way we work. In today's working environment, an office without a personal computer (PC) is unthinkable. Information and communication technology plays an increasingly important role in making organizational goals explicit, in propagating them and above all in measuring them.

The Internet is an organizational 'force' providing a material base for working. It enables flexibility in networks because they operate within and outside existing firms. The network enterprise can assign goals to its networks. So, Internet may promote the decentralization in organizations. The Internet alters competitive advantages because innovation becomes a delicate blending of co-operation and competition. The competitive advantage is likely to be with those already wealthy nations whose social capital can accommodate the new organizational innovations in work and life-styles.

Organizational working now has become a complex process. This means that they are made up of large numbers of people and resources that interact and adapt to each other and to their environment. The implementation of IT is an inevitable option that may connect organizations' human resources to physical resources and environment. In the past organizations were able to operate relatively independently and concentrate on making a good and complete product or service with a limited number of people within their own setup. Nowadays, organizations can rarely manufacture a complete product on their own. Instead, organizations are working together to manufacture a product within a value system. Organizations focus on its core system and operational chain and leave the rest to suppliers and other parties involved in realizing a product or services. Thus, organizations are increasingly becoming units within a network that have to adapt to a rapidly changing environment. This kind of knowledge entrepreneurship enhances the interdependency among the organizations. This interdependency shows in figure 1.2: 


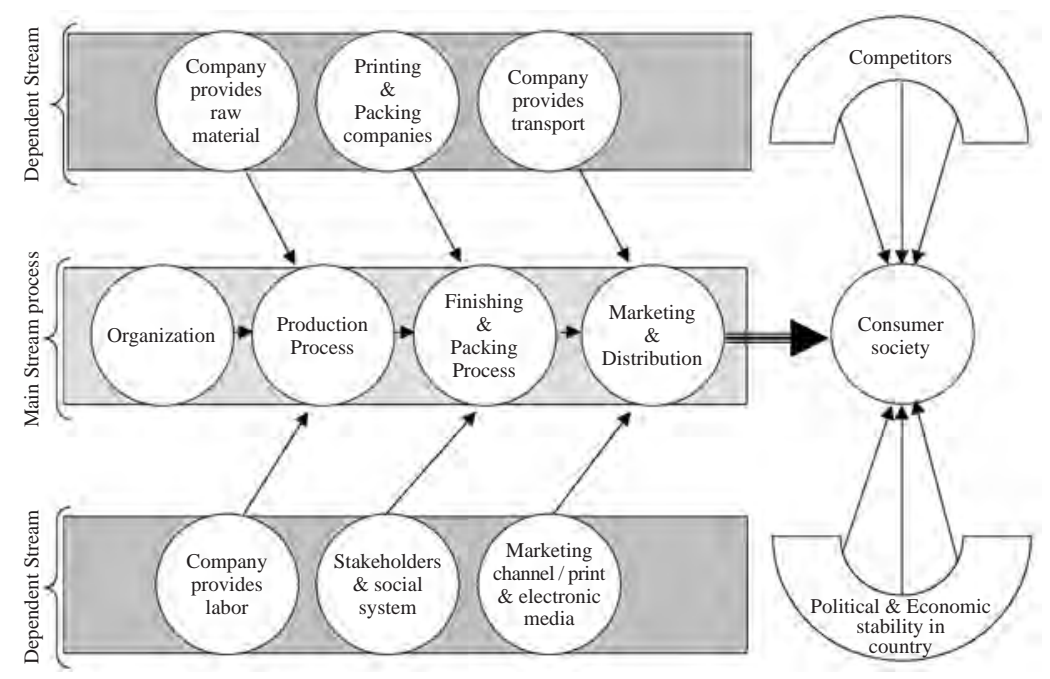

Figure 1.2: Model of Organizational Interdependency

According to a classic book by Micheal Porter (1980), an organization is a combination of primary and supporting processes. In these processes, values are being transformed, for instance from production via distribution to consumption, or from imported raw materials and production resources to end-products. In the overall value system Porter calls these processes value chains.

In the interests of competitiveness, public welfare, and governance, national governments have taken on the role of managing the knowledge resources that circulate globally in abstract forms in order to meet the changing demands of clients and publics in a multiplicity of the context-sensitive applications. The changing demands for knowledge in a fast-paced and global social and economic environment necessitate changes in the way knowledge itself is managed and the ways in which knowledge-workers and their work are organized. Bringing together diverse expertise and experts to solve practical client-centred problems as they arise requires flexible managerial responses as well as new recruitment and retention strategies. Coupled with the introduction of new information and communication technologies, the traditional contexts and places where key knowledge activities are done, styles of work, workplace values, practices, and norms, as well as career expectations are changing rapidly.

Under the changed environment organizations have started paying attention to new human resource management practices that may increase the economic performance of organizations. HRM scholars have argued that human resources are particularly likely to be sources of sustained competitive advantage and that HRM practices should therefore be central to any strategy (Barney 1995). In Pakistan, scant attention is being paid to new HRM practices that how they manage knowledge and its effective use. 
There is one academic criticism on HRM that it lacks theoretical and empirical framework how new HRM practices accommodate the load of information management. How HRM turns knowledge into organizational productivity and improve financial performance.

This study confirms the criticism that theoretical base is lacking in the HRM practices but it is very much there in real situation. There is lot of work that needs to be done on the part of both academia and industrialist. Respondents' views, interviews with top management and our own observation during the survey of the selected sectors and literature available on HRM field strongly suggest a case for indigenous theoretical framework that caters the needs of HRM for accommodating the load of knowledge which is constantly growing. As a broader outline consciously suggest initial thoughts for theoretical construction:

1. Areas characterized by new forms of knowledge and knowledge management.

2. Key sectors within the knowledge-based economy.

3. Sector specific regulatory frameworks.

This approach includes studies on the evolution of the management strategies in Pakistan and HRM activities such as recruitment, internal mobility and retention. Outsourcing and organizational learning opportunities in our current business strategies should also be examined. Knowledge-HRM relationship should be established on Kaisen (continuous improvement) concept. A critical assessment of the relationship between governing institutions and a knowledge-based economy and its key sectors should be made that may be very helpful in the construction of theory on HRM and knowledge management.

This research traces flows of knowledge and the mobility of knowledge professionals within, into, and out of, organizations. This research reveals that the diverse organizational forms in which knowledge work is conducted, such as informal networks and temporary teams, are now assuming the role of computer-mediated 'virtual teams' and other forms of on-demand, need-based 'virtual organizing' in large organizations are growing. The concept of outsourcing is being applied in several organizations specially consultant companies. Recruitment and staffing are also outsourced in number of companies in Pakistan. Employment agencies create considerable number of temporary employment, providing flexible workforce in organizations.

\section{REFERENCES}

Halal E. William. The Rise of the Knowledge Entrepreneur in 'Management', Dushkin McGraw-Hill, 1998/99, p. 232.

Kreitner, Robert \& Kinicki, Angelo. Organizational Behavior, 5th edition, McGrawHill, 2004, pp. 270-271. 
Harvard Business Review, July-August, 2005, p. 47.

The Bell Curve.

Survey Results.

Hillal, William H. The New Management: Democracy and Enterprise are Transforming Organization, Berrett-Koehler, 1996, p. 57-58.

D’Aveni, Richard \& Gunther, Robert E, Hypercompetition: The Dynamics of Strategic Maneuvering, Basic, New York.

Best, Michael, The New Competition, Polity, Oxford, 1990.

Drucker, Peter, The Essential Drucker, Butterworth Heinemann, Boston, 2001, p. 5.

Bowman, Edward H. \& Singh, Harbir. Corporate Restructuring: Reconfiguring the Firm, Strategic Management Journal, 14:5-14.

Zaidi, Akbar, Dismal State of Social Science, City Press, Karachi, 2003, p. 231-34.

Bouwman, Harry (et. al.). Information \& Communication Technology in Organizations, Sage Publications, London, 2005, p. 17.

Laudon C. Kenneth \& Laudon P. Janep. Managing Information System: New Approaches to Organization \& Technology, Printice Hall, New Jersey, 1998, p. 670-671.

Rogers, E.M. Diffusion of Innovations, Free Press, New York, See Chapter 1.

Clark, Peter. Organizational Innovations, Sage Publication, New York, 2003, p. 41.

Porter, Micheal. The Competitive Advantage of Nations, The Free Press, New York, 1990, p. 18.

"The Social responsibility of business encompasses the economic, legal, ethical and discretionary expectations placed on organizations by society at a given point in time."

Archie B. Carroll Business \& Society; Ethics and Stakeholder Management, Cincinnati, Smith-Western Publishing Company. 